\title{
Posttraumatic Renal Artery Thrombosis
}

Mirela Tiglis, Ioana Cristina Grintescu ${ }^{1,2}$, Mihaela Buiuc ${ }^{1}$, Cristian Cobilinschi ${ }^{1}$, Angela Popa ${ }^{1}$, Tiberiu-Paul Neagu ${ }^{3,4}$, Liliana Mirea ${ }^{1,2}$, Ioana Marina Grințescu ${ }^{1,2}$

\begin{abstract}
We present a case of a 40 years old female who was admitted in our hospital after a road accident with thoracolombar, right fibula and tibia trauma injuries. Physical examination relevant for kidney injury was only represented by macroscopic hematuria. Findings on computed tomography (CT) imaging were defining to put the diagnosis of posttraumatic right renal artery thrombosis. She underwent classical total nephrectomy do to the prolonged renal ischemia time ( $>48$ hours after the accident).
\end{abstract}

Keywords: renal artery thrombosis, abdominal trauma, fracture of the lumbar spine, total nephrectomy

\section{INTRODUCTION}

Posttraumatic renal artery thrombosis is a very rare complication of abdominal trauma which occurs especially in young people, after car accidents, with an increasing incidence in the last few years. There are about 400 reported cases in the literature ${ }^{1}$, meaning less than $0.08 \%$ of all reported abdominal traumas and being found in $1-4 \%$ of patients with renal damage ${ }^{2}$. The therapeutic management includes surgical revascularization, nephrectomy or non-operative conservative therapy. A high degree of suspicion associated with computed tomography (CT) scan is mandatory for early detection in order to recover most of the kidney function and to prevent the development of delayed renovascular hypertension or infection.

\section{CASE REPORT}

A 40 years old female was admitted in our hospital approximately 48 hours after a car accident. The patient complained about pain in the thoraco-lumbar spine, right thigh and left leg. Her physical examination revealed a normal systolic blood pressure and heart rate with a normal level of consciousness (the Glasgow Coma Scale (GCS) was 15). She had an extensive hematoma on her right thigh, multiple traumatic marks, wounds in the lower limbs and acute left leg compartment syndrome. The patient had macroscopic hematuria in the Foley catheter after urethral catheterization and the serum creatinine was $1.0 \mathrm{mg} / \mathrm{dL}$. She had an Injury Severity Score (ISS) score of 54 points. Laboratory studies had shown that hemoglobin level was 8.4
${ }^{1}$ Department of Anesthesiology and Intensive Care, Emergency Clinical Hospital of Bucharest, Romania

${ }^{2}$ Clinical Department No. 14, "Carol Davila" University of Medicine and Pharmacy, Bucharest, Romania

${ }^{3}$ Clinical Department No. 11, "Carol Davila" University of Medicine and Pharmacy, Bucharest, Romania

${ }^{4}$ Department of Plastic Surgery and Reconstructive Microsurgery, Emergency Clinical Hospital of Bucharest, Romania

\section{Corresponding author.}

Tiberiu Paul Neagu, Department of Plastic Surgery and Reconstructive Microsurgery, Emergency Clinical Hospital of Bucharest, $8^{\text {th }}$ Floreasca Avenue, $1^{\text {st }}$ District, 014464, Bucharest, Romania.

E-mail: dr.neagupaul@gmail.com 
$\mathrm{g} / \mathrm{dL}$, the hematocrit level, $26.8 \%$, the leukocyte count, $10.800 / \mu \mathrm{L}$ (predominantly neutrophils) and the platelet count was normal. The potassium level was also normal with the creatine kinase level of $1362 \mathrm{U} / \mathrm{L}$ and an alanine aminotransferase level of $125 \mathrm{U} / \mathrm{L}$. Focused abdominal ultrasonography for trauma patients has been performed with unclear results. A full body CT scan was performed and revealed minimal bilateral pleural effusion, hepatic contusion, normal contrast uptake from the left kidney, while, the right kidney showed lack of enhancement with a right renal artery dissection fold (Figure 1), right perinephric fluid collection about $1.2 \mathrm{~cm}$, an extensive prevertebral hematoma in the lumbar-aortic space from the twelfth thoracic vertebra to the fifth lumbar vertebra, a comminuted fracture of the second lumbar vertebrae corp (Figure 2,3), a transverse process fracture of the fourth thoracic vertebrae,

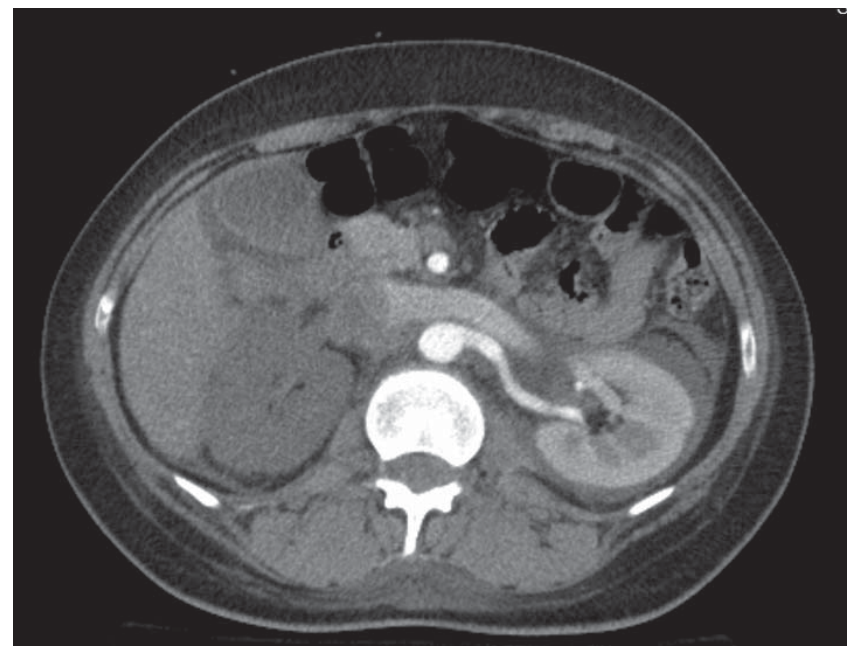

Figure 1. Computed tomography revealing lack of enhancement of the right renal artery and kidney.

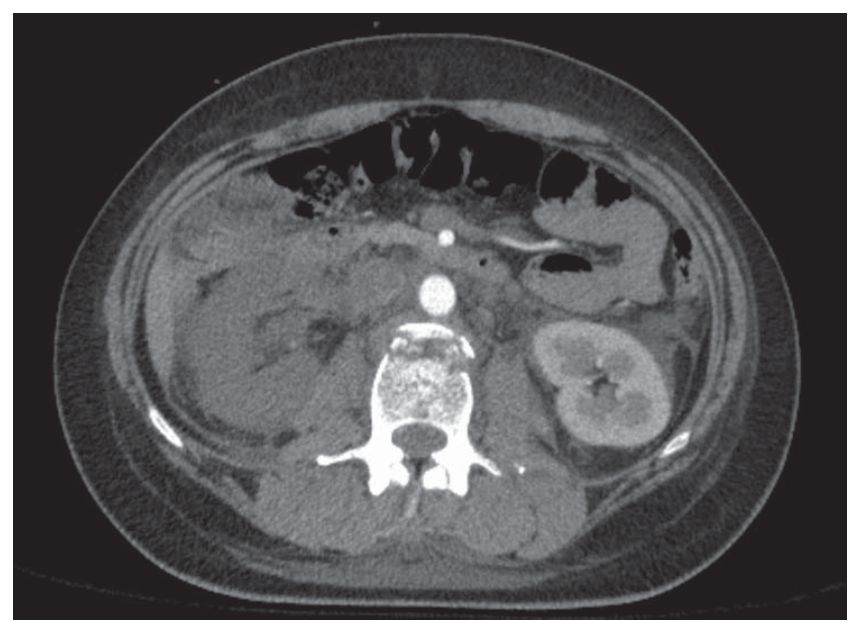

Figure 2. Computed tomography revealing a comminuted fracture of the second lumbar vertebrae corp.

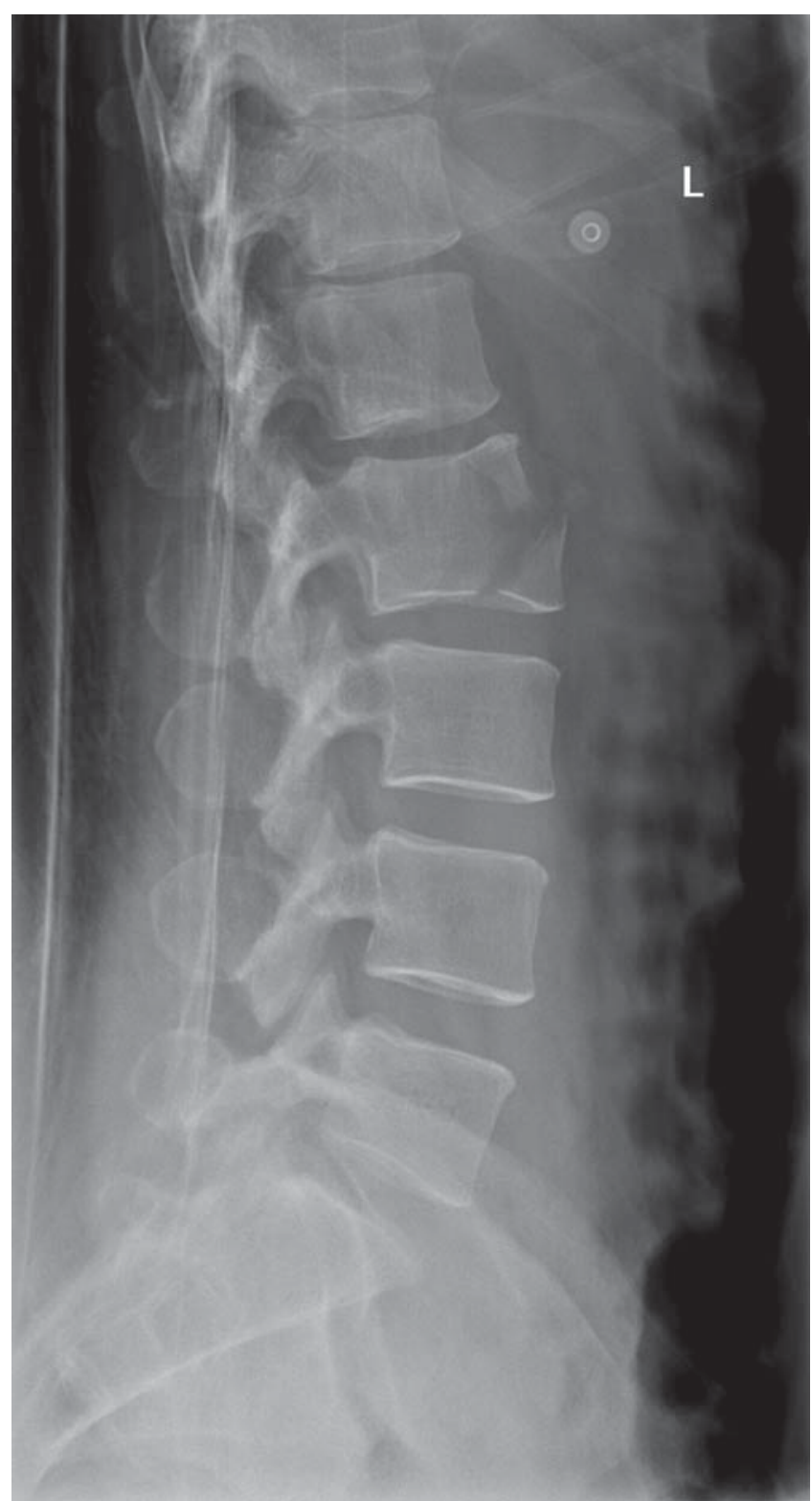

Figure 3. Plain radiographs revealing fracture of the second lumbar vertebrae corp.

a minimal sacred bone fracture, a comminuted left tibia (Figure 4) and fibula fracture. Therefore, the patient was taken promptly into surgery and under general anesthesia, right total nephrectomy was performed and the left lower limb was immobilized in a temporary cast. After that she was admitted in the Intensive Care Unit (ICU) for close observation and monitoring. The patient received blood transfusion, diuretic therapy, antibiotherapy, stress ulcer prophylaxis and multimodal analgesic therapy. After three days she was transported into the operating theatre for a second stage surgery with ostheosynthesis of the left tibia and fibula with plates and screws along with right thigh hematoma evacuation and large tegument necrectomy. The pati- 


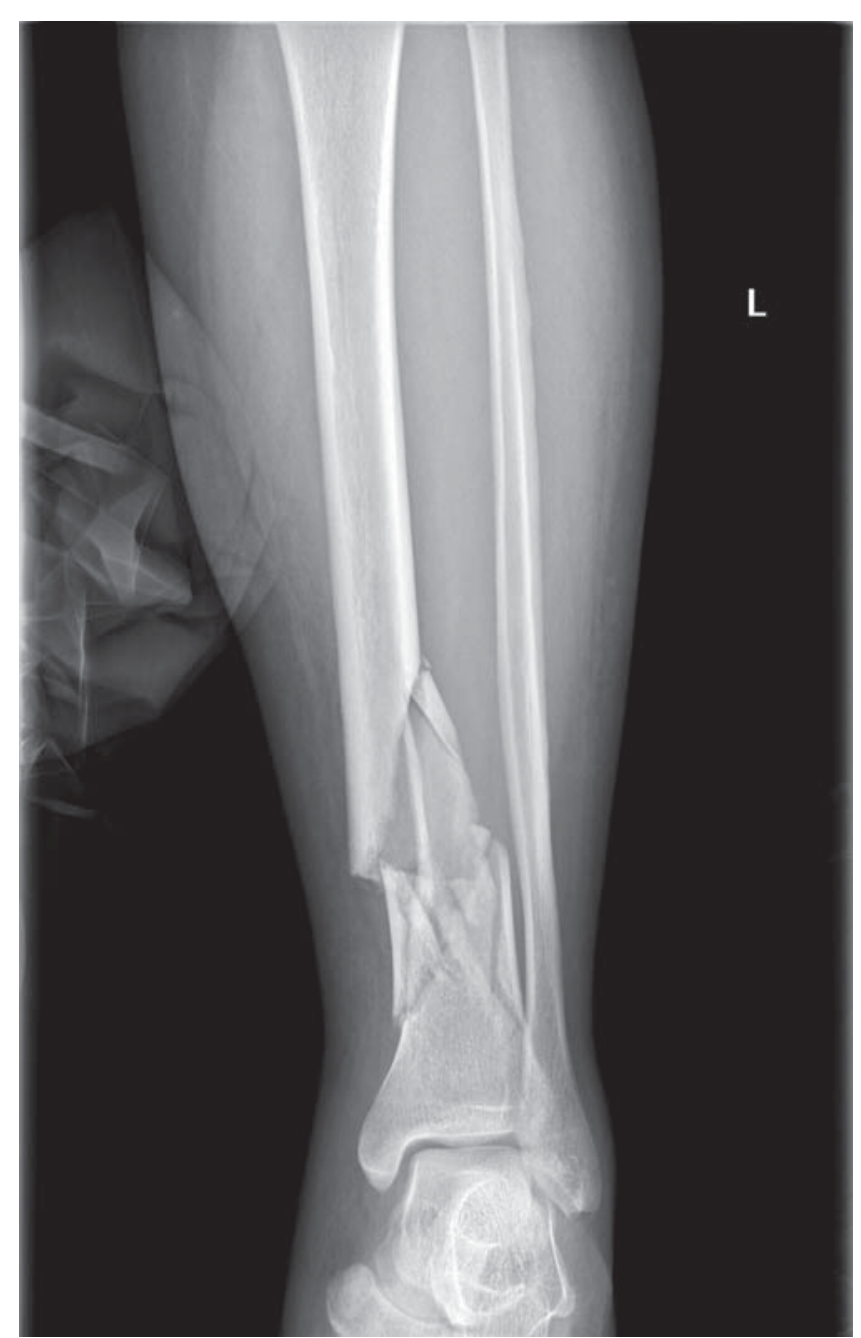

Figure 4. Plain radiographs revealing comminuted fracture of the distal third of the tibia.

ent evolution was favorable, she was cardio-pulmonary stable, the left kidney function was normal, creatine kinase level returned to normal, creatinine level was completely normal, the hemoglobin level was corrected and the progress of the right thigh wound was acceptable. After two weeks she was dismissed form the ICU with a thoraco-lumbar spinal brace. The thigh soft tissue defect was covered using an expanded skin graft.

\section{DISCUSSION}

Our patients had a posttraumatic right renal artery thrombosis but the majority of reported cases describe that left kidney is more prone to injury necessitating high velocity trauma and almost all the patients have other important injuries ${ }^{3}$. She underwent a second stage surgery for ostheosynthesis of the left tibia and fibula with plates and screws (with a good healing outcome $)^{4}$ along with right thigh hematoma evacuation and large necrectomy of the soft tissue. Like in our case, intimal and then subintimal dissection, compression and thrombosis of the renal vessels, especially arteries, between the abdominal wall and the vertebral bodies are usually the associated causes ${ }^{1}$. For our patient, it seems that a bone fragment from the comminuted fracture of the second lumbar vertebrae corp has migrated and damaged the right renal artery leading to thrombosis.

The physical examination and laboratory data (the level of potassium and creatinine may be increased, metabolic acidosis being frequently encountered in trauma patients ${ }^{5}$ ) are not specific enough to put the diagnosis of renal artery occlusion, therefore the golden standard study remains computed tomography scan with contrast ${ }^{6}$. Findings of abdominal trauma, flank hematoma or pain and hematuria are nonspecific signs for acute kidney trauma ${ }^{1}$.

Nephrectomy is not an ideal choice procedure for renal vascular trauma, but it is an option in selected cases with delayed diagnosis (in our case the time of renal infarction was $>48$ hours) in order to prevent renovascular hypertension ${ }^{7}$. Prolonged ischemia time ( $>12$ hours) is associated with small chances of kidney function recovery and can lead to chronic dialysis8. The critical time regarding renal ischemic tolerance is a limited window of 2-3 hours for revascularization and for saving the kidney`s function ${ }^{9,10}$.

Our patient presented macroscopic hematuria. It occurs in approximately $60 \%$ of patients with renal vascular injury ${ }^{1}$.

There are a wide variety of techniques for the repair of renal artery: splenorenal by-pass, re-implantation of the native renal artery into the abdominal aorta, usage of synthetic material, but this are limited by patient's renal tolerance to the ischemic insult ${ }^{10}$.

The severity of the injury is established using the American Association for the Surgery of Trauma (AAST) Organ Severity Score that varies from grades 1 to 5 . Renal venous or arterial injury is classified as either grade 4 or grade 5 . Grade 4 signifies that some segmental veins or arteries are injured while grade 5 refers to the main renal vein or artery lesion ${ }^{11}$. In our case the right renal main artery was affected.

\section{CONCLUSION}

Posttraumatic renal artery thrombosis is a rare condition usually associated with others important injuries. It requires a high impact force that occurs especially in road accidents. The right treatment has not yet been established, but it should be individualized depending on the traumatic context. Total nephrectomy is necessary 
in almost all cases with prolonged renal infarction time $>12$ hours. Early diagnosis and prompt revascularization or nephrectomy are crucial in obtaining optimal outcome without secondary hypertension or impairment renal function.

\section{References}

1. Jawas A, Abu-Zidan FM. Management algorithm for complete blunt renal artery occlusion in multiple trauma patients: case series. International journal of surgery. 2008 Aug 31;6(4):31722.

2. Raavi S, Krishnaswami M, Gnanaprakasam F, Ramachandran $M$. Acute posttraumatic renal artery dissection treated by primary stenting. Indian Journal of Vascular and Endovascular Surgery. 2016 Jan 1;3(1):33.

3. Abu-Gazala M, Shussman N, Abu-Gazala S, Elazary R, Bala M, Rozenberg S, Klimov A, Rivkind Al, Arbell D, Almogy G, Bloom Al. Endovascular management of blunt renal artery trauma. Isr Med Assoc J. 2013 May 1;15(5):210-5.

4. Neagu TP, Tigliş MI, Cocoloş I, Jecan CR. The relationship between periosteum and fracture healing. Rom J Morphol Embryol. 2016 Jan 1;57(4):1215-20.

5. Checheriță IA, David CR, Diaconu V, Ciocalteu A, Lascăr I. Potassium level changes--arrhythmia contributing factor in chronic kidney disease patients. Rom J Morphol Embryol. 2011;52(3 Suppl):1047-50.

6. Klapsis V, Bouropoulos K, Ferakis N, Poulias I. Renal artery thrombosis as a result of blunt abdominal trauma. Hellenic Urology. 2015 Nov 18;27(2).
Our case illustrates that, in order to save the renal function, is optimal to promptly diagnose an artery thrombosis and that physical examination is not specific for renal vascular trauma. The golden standard method of diagnosis is computed tomography scan with contrast.

7. Gidaro S, Schips L, Cindolo L, Ziguener R. Laparoscopic nephrectomy for complete renal infarction due to post traumatic renal artery thrombosis. Archivio Italiano di Urologia Andrologia. 2008 Jun;80(2):79

8. Checherită IA, David CR, Ciocâlteu A, Lascăr I, Budală LA. Oral treatment of metabolic acidosis in hemodialyzed patients and the implications on the hemodynamic status. Rom J Morpho Embryol. 2013;54(3):539-43.

9. Janda SP. Bilateral renal vein thrombosis and pulmonary embolism secondary to membranous glomerulonephritis treated with percutaneous catheter thrombectomy and localized thrombolytic therapy. Indian journal of nephrology. 2010 Jul;20(3):152.

10. Jahangiri Y, Ashwell Z, Farsad K. Percutaneous renal artery revascularization after prolonged ischemia secondary to blunt trauma: pooled cohort analysis. Diagnostic and Interventional Radiology. 2017 Sep;23(5):371.

11. Buckley JC, McAninch JW. Revision of current American Association for the Surgery of Trauma Renal Injury grading system. Journal of Trauma and Acute Care Surgery. 2011 Jan 1;70(1):35-7. 